Authors have nothing to disclose with regard to commercial support.

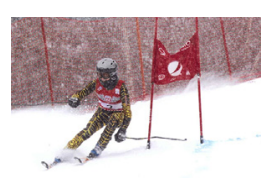

\section{ENHANCED RECOVERY PATHWAYS VERSUS STANDARD CARE: THE DIFFERENCE LIES IN WHAT IS BEING TARGETED BY THE PATHWAYS}

\section{To the Editor:}

We read with interest the experience of our colleagues Brunelli and associates, ${ }^{1}$ from Leeds, United Kingdom, with enhanced recovery pathways (ERPs) used for patients who had undergone pulmonary resections. They found no benefits of ERP use with respect to such outcomes as cardiac and pulmonary complications, mortality, length of stay, and rate of readmission. They argued that the cost of $\$ 189$ per patient necessary for the implementation of an ERP was probably not justifiable.

The objective of ERPs is to eliminate as soon as possible all factors that ground patients to their hospital beds. ERPs include aggressive management of all drains (chest tube and Foley catheters) and optimization of pain control. Good pain control is essential in achieving the goal of any ERP, which is an early and safe discharge and a fast resumption of the activities of daily living. We have found this to be achieved best with a polypharmacy aiming at altering the sensation of pain at multiple levels through the pain pathways. This also results in a reduction of dependency on narcotics, which are a significant source of side effects. ${ }^{2}$

When reviewing the data from our colleagues, ${ }^{1}$ we noticed that the interventions added to their ERP were those we considered to be too limited in value to show a difference in the operative outcomes measured. For instance, we observed that the pain management strategy before and after ERP implementation was the same and relied on patient-controlled analgesia, paravertebral blocks with short-acting local anesthetics, and narcotics administered rectally. Brunelli and associates ${ }^{1}$ did not report on the pain scores of their patients, nor did they specify the amount of narcotics their patients needed.

\footnotetext{
The Editor welcomes submissions for possible publication in the Letters to the Editor section that consist of commentary on an article published in the Journal or other relevant issues. Authors should: $\bullet$ Include no more than 500 words of text, three authors, and five references. • Type with double-spacing. • See http://jtcs.ctsnetjournals.org/ misc/ifora.shtml for detailed submission instructions. • Submit the letter electronically via jtcvs.editorialmanager.com. Letters commenting on an article published in the JTCVS will be considered if they are received within 6 weeks of the time the article was published. Authors of the article being commented on will be given an opportunity of offer a timely response ( 2 weeks) to the letter. Authors of letters will be notified that the letter has been received. Unpublished letters cannot be returned.
}

Other interventions, such as motivational talks, warming, and carbohydrate loading, are helpful in reducing the perioperative stress; however, their limited impact on perioperative complications may be undetectable in such a small group of patients as that of Brunelli and associates. ${ }^{1}$ The modifications of the ERP presented by Brunelli and associates $^{1}$ therefore had little effect on reducing the risk of mortality and pneumonia. Our colleagues may have to look at other factors in ERPs to reduce these rates.

What Brunelli and associates ${ }^{1}$ have reported is the effect of an updated care map on their practice. Care maps improve the flow and the overall experience of patients and staff, but they are not meant to decrease perioperative complications. On the other hand, they save money and reduce variables, eliminating mistakes and improving quality. ${ }^{3}$

ERPs can have a significant impact on the perioperative outcome of patients, but the magnitude of the effect of the intervention is based solely on what is being targeted by the pathways. An optimal pain management strategy, for instance, might have differently affected the outcome and the conclusion reported by Brunelli and associates. ${ }^{1}$

Reza J. Mehran, MDCM, MSC ${ }^{a}$

Linda W. Martin, MD, MPH

${ }^{a}$ Department of Thoracic and Cardiovascular Surgery University of Texas MD Anderson Cancer Center

Houston, Tex

${ }^{b}$ Department of Thoracic and Cardiovascular Surgery University of Virginia Charlottesville, $\mathrm{Va}$

\section{References}

1. Brunelli A, Thomas C, Dinesh P, Lumb A. Enhanced recovery pathway versus standard care in patients undergoing video-assisted thoracoscopic lobectomy. J Thorac Cardiovasc Surg. 2017;154:2084-90.

2. Mehran RJ, Martin LW, Baker CM, Mena GE, Rice DC. Pain management in an enhanced recovery pathway after thoracic surgical procedures. Ann Thorac Surg. 2016;102:e595-6.

3. Cerfolio R. Call it "fast tracking" or "enhanced recovery pathways" — no matter the name, it ain't nothing new to thoracic surgeons. J Thorac Cardiovasc Surg. 2017; 154:2091.

https://doi.org/10.1016/j.jtcvs.2018.01.013

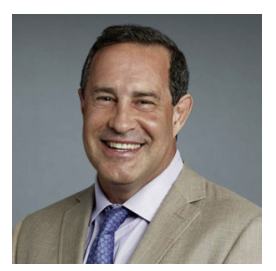

DO WE MEASURE WHAT MATTERS TO PATIENTS AND WHY?

Reply to the Editor:

I enjoyed and agreed with the letter of Drs Mehran and Martin. I offer a slightly different perspective. You can only improve something that you can measure. The real question is this: Are we measuring or targeting things that truly matter to patients when we implement enhanced recovery programs, or are we targeting factors that resonate more with other stakeholders in health care? 
Dr Cerfolio is a consultant for Intuitive, Ethicon, Covidien, Bovie, KCL, Myriad, Neoment/Bard, Novartis, Pinnacle, TransEnteric, Medtronic, Google, and C-SATS video review. Dr Cerfolio is also the president of the ROLO-7 Consulting Firm.

Does a patient really care if he or she goes home on postoperative day 2 versus day 3 ? It depends on who is at home for that patient, and how good the service is in the hospital being left.

Does a patient truly care if he or she gets out of bed on the day of a minimally invasive lobectomy and walks, versus the next morning? No, not unless that walk the night before provides some value and somehow enhances the ability to recover fully from the operation. Do we have any data that it does? No. Patients with lung cancer who undergo surgery have simple desires. They want to have no pain, to have their cancer all out, to be cured with no further therapy, and to return to full activities without any problems as soon as possible. Do the metrics that we are currently measuring, tracking, and giving 3-star ratings really measure these values? Do early recovery programs and fast-tracking pathways help patients, or do they provide more value to the hospital, the payers, and the doctors?

I, like others, have been an advocate of enhanced recovery programs, care flow programs, and lean initiatives for more than 2 decades. The current ERAS colorectal programs are not new to thoracic surgeons who have been doing preoperative exercise, smoking cessation, intraoperative lean initiatives, and postoperative protocols to reduce cost, speed recovery, decrease pain, and get tubes out sooner for more than 30 years. Yet, we must recognize that some of these initiatives may provide greater value to stakeholders other than the patient. We need to refine the metrics that we measure and target. Most importantly, we must ensure that the targets are patient focused.

Our goals as surgeons and physicians should be centered solely on our customer, who sometimes gets lost in the complex process of health-care delivery. Once all the stakeholders in health care are aligned, and we remember whom we serve and why we serve them, then the factors that we target, the metrics that we measure, and the outcomes that we deliver will help the only people in the process who matter-our patients.

Robert James Cerfolio, MD, MBA Department of Cardiothoracic Surgery New York University Langone Health New York, NY

https://doi.org/10.1016/j.jtcvs.2018.01.041

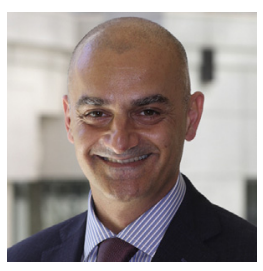

ENHANCED RECOVERY PATHWAYS IN THORACIC SURGERY: TIME FOR A VERSION 2.0

Reply to the Editor:

I thank Drs Mehran and Martin ${ }^{1}$ for their interest in and comments on my group's article regarding enhanced recovery pathways (ERPs) for patients undergoing video-assisted thoracoscopic lobectomy. ${ }^{2}$ I totally agree with their statements. Our study, however, should not be interpreted as a negative message against ERPs. We strongly believe that the application of standardized pathways of care in our specialty can contribute to improving quality of care, patient safety, and team efficiency-and ultimately could save money. On a patient level, it seems clear that the use of traditional end points, such as early outcomes and length of stay, is not able to capture entirely the benefits of ERPs. The most probable explanation, as mentioned in our study, ${ }^{2}$ is that most of the elements composing what is defined as an ERP have individually already been in use for many years in most thoracic surgery centers. In addition, our study was restricted to patients undergoing video-assisted thoracoscopic surgical lobectomy. Minimally invasive surgery is arguably the most important element of an ERP, likely blurring the effects of other elements. Unfortunately, as discussed in the limitations section of our study, ${ }^{2}$ important subjective end points were not available to measure the effect of an ERP on patient-reported outcomes such as pain score, satisfaction with care, and quality of life.

Probably one of the most important messages of our study $^{2}$ is the need to progress from the current myopic performance evaluation that looks only at short-term outcomes to a more patient-centric appraisal of efficiency and value. Value can be translated into the ratio of quality to cost, ${ }^{3}$ where quality for our patients is represented by cancer-specific survival and quality of life. Ideally, future care map updates should be implemented that target value as the main metric.

Thoracic surgeons have been using elements of ERPs for decades, and it is likely that what is commonly defined as an ERP is now already "standard care" in most thoracic centers. ${ }^{4}$ We therefore need to evolve further by introducing additional standardized patient-centric elements of care that will represent a more efficient version 2.0 of ERPs.

Alessandro Brunelli, MD Department of Thoracic Surgery St James's University Hospital Leeds Teaching Hospital NHS Trust Leeds, United Kingdom 